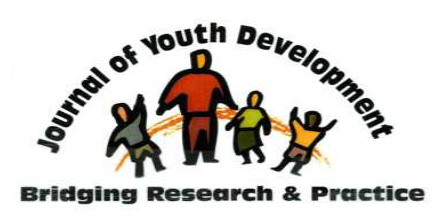

Volume 11, Number 3, Winter 2016
JOURNAL OF YOUTH DEVELOPMENT

Bridging Research and Practice

\section{An Examination of Self-Esteem and Empowerment of African American Female Youth in an After School Program}

Taylor Unroe

The University of Florida

tunroe@ufl.edu

Rosemary V. Barnett
University of Florida
rbarnet@ufl.edu

Caroline Payne-Purvis

Department of Health and Kinesiology

Mississippi University for Women

cpaynepurvis@muw.edu

\begin{abstract}
This study investigated self-esteem and empowerment in three African American female cohort groups in an after school program. A sample of 136 students in the after school program comprised the three one-year female and male cohort groups. For this study, 71 African American females in the female cohort groups were analyzed. Social Cognitive Theory and Resiliency Theory were used to explore factors potentially influencing self-esteem and empowerment of an at-risk African American female population, with the after school program serving as a protective factor. Participants completed the Rosenberg Self-Esteem Scale and the Developmental Assets Profile (DAP), but only DAP empowerment items were analyzed. No significant differences were found in selfesteem levels for the three separate female cohort groups. However, evidence was found for a positive correlation between self-esteem and empowerment. Study conclusions identify implications for after school program staff as they identify needs and conduct youth programs accordingly.
\end{abstract}




\section{Introduction}

Adolescent females are under constant scrutiny in our society to conform to certain physical appearances, mindsets, and gender behaviors. They are also consistently exposed to social and environmental factors that affect self-esteem and empowerment both positively and negatively. Such social and environmental factors include: school, peers, families, and social clubs (Lee, Dickson, Conley, Holmbeck, 2014). Negative aspects of these factors and pressures can lead to a lack of self-esteem and empowerment. To address the issue of lacking self-esteem and empowerment, a number of techniques have been researched to determine factors related to increased self-esteem in females (O'Dea \& Abraham, 2000; Miller \& Lavin, 2007). Researchers postulate that higher levels of self-esteem can be used to explain a wide variety of behaviors and is used to explain those behaviors (Sharaf, et al, 2009). Behaviors such as deviance, aggression, altruism, love, hatred, and conformity have all been rooted in the human need to feel valued (Pyszczynski, Greenberg, Solomon, Arndt, \& Schimel, 2004). Though there is not a widely agreed upon definition for a related construct, empowerment, Gullotta and Adams (2005) ascertain a general definition that empowerment is simply the ability to take control of ones destiny. Very little research exists examining factors related to empowerment and selfesteem among the same population. However, by examining self-esteem and empowerment more in depth, further understanding their impacts on the lives of adolescents may be shown.

\section{Self-Esteem in Adolescence}

Self-esteem is most commonly defined as an evaluation of one's own self-worth (Sharma \& Agarwala, 2013; Gullotta \& Adams, 2005). It is a widely accepted attribute for a healthy and balanced adolescent (Gullotta \& Adams, 2005), and self-esteem for females is incredibly important because they are under a great amount of pressure from social media, their peers, and from their families to meet certain gender expectations. Ways to increase self-esteem come in many forms, but for the purpose of this study females participating in an after school program will be examined in order to observe the changes, if any, in their self-esteem during participation.

High levels of self-esteem have been repeatedly associated with high levels of resilience or positive adaptation (Boden, Fergusson \& Horwood, 2008; Scales \& Leffert, 1999), and low levels have related to depression, hostility, bitterness, disenchantment, and alienation from others (Bos, Huijding, Muris, Vogel, \& Biesheuvel, 2010; Gullotta \& Adams, 2005; Orth, Robins, \& Roberts, 2008; Orth, Robins, Trzesniewski, Maes, \& Schmitt, 2009). This is especially common among adolescent females (Raty, Larson, Solderfeldt, \& Larsson, 2005). Low selfesteem during adolescence has also been associated with depression, eating disorders, risk behaviors, and lower academic performance (Vanhalst, et al., 2013; Paxton, Eisenberg, \& Neumark-Sztainer, 2006). Low levels of self-esteem have also been linked to behavior problems, poor school performance, teenage pregnancy, higher risk of suicide, and maladjustment (Agarwala \& Raj, 2003; Crockenberg \& Soby, 1994; Bhattacharjee \& Deb, 2007; Brausch \& Decker, 2014; Choquet, Kovess, \& Poutignat, 1993; National Crime Records Bureau, 2007). Ultimately, the potential relationships associated with high self-esteem and low selfesteem in adolescence indicate it is an integral component of adolescent development. 


\section{African American Females and Self-Esteem}

Across all cultures, races, and ethnicities, self-esteem is instrumental in positive adolescent development and success (Gullotta \& Adams, 2005). The transition to adolescence is when selfesteem becomes the most salient (Green \& Way, 2005). Many factors affect self-esteem like peers, social groups, body image, feeling of belonging, success in school, and also interactions with family. For African American adolescents, it can be a daunting task to develop in a society in which they are a minority and experience racial discrimination.

Right now, a gap exists in research to examine why African American students of all genders do not show more depression and anxiety than other youth. Gaylord-Hardin and colleagues (2006) also explain that these students will undoubtedly be experiencing more contextual risk factors that should be causing more anxiety and depression than other students not of the African American race (Gaylord-Hardin Ragsdale, Mandara, Richards, \& Peterson, 2006). It has been proposed by Gaylord-Hardin and colleagues (2006) that higher levels of self-esteem can serve as a buffer between depression and anxiety (Gaylord-Hardin et al., 2006). Higher levels of selfesteem have also been linked to more exposure to high levels of race pride and socialization during the crucial developmental adolescent years (Harris-Brit et al., 2007).

\section{Empowerment}

Empowerment is deeply rooted in ideals such as autonomy, self-regulation, roles, helping, giving, contributing, youth leadership, youth involvement, youth participation, and self-efficacy (Gullotta \& Adams, 2005, Bay-Cheng, 2012; Lamb \& Peterson, 2012). Bandura (1977, 1986, 1997) has suggested self-efficacy affects what individuals will do, their effort to achieve a particular outcome, and their persistence in achieving tasks when faced with obstacles. Large amounts of self-efficacy can serve as a protective factor for risky behaviors. In contrast to these concepts, a lack of empowerment would be associated with concepts such as helplessness, violence, and threats. The term empowerment also refers to both social and subjective power (Lamb \& Peterson, 2012). For adolescents, feelings of personal confidence and competence are created through the support and solidarity garnered from the relationships they form with others (Bay-Cheng, 2012). These relationships are based on unanimity or homogeneity; however, the importance of these relationships is that they are diverse, proactive, and ultimately lead to a productive collaboration between individuals. Diverse interactions with peers provide adolescents with the confidence to determine their own values. Their self-determined beliefs make them feel empowered.

Vulnerable youth benefit more as more empowerment assets are provided (Scales \& Leffert, 1999). Vulnerable youth are described as having the least developmental assets and are helped more by these assets than youth with normal or high levels of assets. Broader opportunities to access empowerment assets are associated with "healthy" communities (Scales \& Leffert, 1999). These same researchers also postulate that vulnerable youth living in healthy communities are less likely to engage in risky behaviors as youth their same age, who are equally as vulnerable, who live in unhealthy communities (Scales \& Leffert, 1999). These conclusions point to the importance of empowerment within communities with vulnerable youth. 


\section{Empowerment and African American Females}

Empowerment is not a topic that has been explored in depth for any racial or ethnic group of people and even less literature exists for such a unique population: African American adolescent females. From the literature that does exist, empowerment is a driving force in the effort to enable African American females self-efficacy and belief in their ability to perform specific tasks (Lindsey, 2013). Empowerment is said to consist of three important components: interpersonal interactions (self-efficacy), intrapersonal interactions, and behaviors (Bay-Cheng, 2012). These components are greatly affected by outside influence, especially for adolescent females. Their opinions of themselves and their feelings of empowerment can be diminished if they do not feel they are meeting expectations that society has placed on them.

Females in general are under constant scrutiny to look and act a certain way, and for African American females these social constructs are even more rigid based on indications from research. Dominant social representations of African American females may consist of sexual promiscuity, aggressiveness, delinquency, poor lifestyle choices, and consistent stress amidst stoicism (Cassidy \& Stevenson, 2005; Hall, 2009; Matthews, Kizzie, Rowley, \& Cortina, 2010; Swinton, Kurts-Costes, Rowley, \& Okeke-Adeyanju, 2011; Travis \& Leech, 2013). With few representations in general of adolescent African American females in popular media, there is not a lot of positive modeling happening (Lindsey, 2013). Lindsey (2013) suggests that popular characters on television shows can empower young African American females through their visibility, but they do not necessarily provide racially specific examples of empowered African American females. African American females face a number of obstacles related to social prejudice as they pursue empowerment.

\section{Theoretical Background}

This study used Social Cognitive Theory and Resiliency Theory as the theoretical frameworks for the study design. Social Cognitive Theory (SCT), also referred to as Social Learning Theory, is rooted in the belief that learning occurs within a social context and that people learn from each other (Bandura, 1997; Chavis, 2011). Adolescents learn both positive and negative behaviors from peers, which can boost or diminish self-esteem. In this study, SCT will be applied in order to analyze the relationships between interacting with peers that are similar to them demographically in their social environment (the after-school program) and their self-esteem and empowerment. Resiliency refers to the ability to spring back from adversity or to adapt effectively in the face of adversity (Garmezy, 1993; Werner \& Smith, 1992). Resiliency theory is based on the concept that every youth has a number of risk factors in their lives with a respective protective factor that is hopefully present as well. Risk factors are not risk behaviors, but the potential catalyst for youth to participate in risk behaviors, or problems that result in negative outcomes (Arnett, 2010). Protective factors are characteristics of youth that are related to lowering the likelihood of the participation in risk behaviors (Arnett, 2010).

\section{Purpose \& Rationale}

The purpose of this study is to examine perceptions of three cohort groups of at-risk African American adolescent females in regard to their self-esteem and empowerment levels during participation in an after-school program. After school programs have been found to benefit adolescents and allow them to participate in activities that increase self-esteem (John, Wright, 
Rowe, \& Duku, 2009). Adolescents in low-income communities also have a higher need for after school programs and engagement in activities that promote healthy development (Eccles \& Gootman, 2002; Mahoney, Larson, \& Eccles, 2005; John et al., 2009). Additionally, African American adolescent females face unique challenges in self-esteem and empowerment, which merit further research to gain understanding on how after school programs and professionals can best support African American adolescent females. The research questions for the study are as follows: 1) Is there a statistically significant difference in the self-esteem levels of three oneyear cohort groups of African American female youth participants in an after school program?;

2) Is there a statistically significant difference in the empowerment levels of three one-year cohort groups of African American female youth participants in an after school program?; 3) Is there a statistically significant relationship between the variables of self-esteem and empowerment for three one-year cohort groups of African American female youth participants in an after school program? The hypotheses to accompany each respective research question were as follows: 1 ) There is a statistically significant difference in the self-esteem levels of three one-year cohort groups of African American female youth participants in an after school program; 2) There is a statistically significant difference in the empowerment levels of three one-year cohort groups of African American female youth participants in an after school program; 3) There is a statistically significant relationship between self-esteem and empowerment for three one-year cohort groups of African American female youth participants in an after school program.

\section{Methodology}

This study utilizes a cross-sectional design. Researchers that use the cross-sectional design method are interested in variation (Bryman, 2012). The population for this study came from the participants in a Children, Youth, and Families at Risk (CYFAR) after school program in Florida. The data were collected in years 2011, 2012, and 2014. Approximately 136 participants were enrolled in the program. These three years allowed the researchers to compose three separate cohort groups. Year 1 was cohort group 1 (2011), year two was cohort group 2 (2012), and year 3 was cohort group 3 (2014). During the three years that data were collected, each student completed 10 surveys.

The purpose of the program was to serve at risk teens and their families by providing a comprehensive after-school program in their community when no other exists. The main focus of the program was to examine the relevant issues within the community. Teens in the program were given the opportunity to learn how to become involved in the community decision-making process. There were two communities in two different counties involved. The two after school programs were part of a federally funded grant project focused on low SES communities with high at risk youth. The youth population in community one was predominately Hispanic, and for this reason, this group was not used in this study. Community two was a rural community with high rates of drug use and crime, and was predominately African American, and the youth enrolled in the program were used in this study.

\section{Data Collection}

Data collection took place in the summers of 2011, 2012, and 2014 with youth enrolled in the after school program. The researchers obtained parental consent in order to gain permission to survey the youth under the age of 18 . Researchers were to travel to the location in order to 
collect data on site one day each year. All 136 students were given the surveys, but for the purpose of this study only the surveys completed by African American females were used. There were 67 African American females who completed surveys and comprised the three oneyear cohort groups that were used in this study.

Internal Review Board (IRB) approval had already been permitted before data collection began. All participants were notified that their responses were voluntary and confidential. Students did not receive any incentive for completing the surveys, as they were a part of a research grant and anticipated to be surveyed due to this. Surveys were not filled out without parental consent. If consent was not given on the day data were to be collected, surveys were to be completed and mailed on a later date once consent was given.

\section{Instrumentation}

The Rosenberg Self-Esteem Scale (1965) and the Developmental Assets Profile (DAP) (1995) were completed in paper form to explore the research questions.

Self-Esteem was studied through questions 1-10 on the Rosenberg Self Esteem Inventory (1965) questionnaire. This questionnaire is usually used with participants in junior high and adulthood (Hatcher, 2007). The Rosenberg is the most widely used instrument for measuring self-esteem and has been translated into many languages (Schmitt \& Allik, 2005). The Rosenberg has many advantages, the first being that it has a long history of use, has uncomplicated language, brevity, is convenient, and is popular in large population based quantitative studies (Urban, Szigeti, Kokonyei, 2014). The Likert-type responses are summed up to create a total score for each domain. For each item a score is given ranging from zero ("strongly disagree") to three ("strongly agree"). Items 2, 5, 6, 8, and 9 were reverse coded. The total possible score for the Rosenberg Self-Esteem Scale is 30, with higher scores indicating higher self-esteem. Rosenberg also describes three scoring groups self-esteem: low (0-14), medium (15-25), high (26-30).

The African American female population is an underserved and understudied population (Hatcher, 2007). The unique cultural and personal oppressions that African American women face mean self-esteem may include other aspects that are not considered in other mainstream definitions (Hatcher, 2007). The definition for this specific population includes aspects that include racial pride and collective experiences and is shaped by experiences of racism and sexism. The Rosenberg does not specifically cover questions about racism or sexism, but covers overall global self-esteem.

Since 1989, the Search Institute has conducted research stemming from literature on resilience, prevention, and adolescent development (Scales \& Leffert, 1999). This research has highlighted the positive relationships, opportunities, competencies, values, and self-perceptions that youth need in order to succeed while also providing the framework for the developmental assets (Scales \& Leffert, 1999). The Developmental Assets Profile (DAP) is a 58-item questionnaire that addresses developmental assets, both internal and external (DAP, 1995). This measurement was used to assess empowerment. The DAP is the most commonly cited instrument for positive youth development (Scales, Benson, Fraher, Syvertsen, Dershem, Makonnen, Nazneen, \& Titus, 2013). There are eight categories measured on the DAP: support, empowerment, boundaries, constructive use of time, commitment, positive values, social 
competencies, and positive identity. They are also categorized as internal assets (e.g., positive identity) and external assets (e.g., support). The DAP also has a wide array of outcome factors that include "challenged," "vulnerable," "adequate" and "thriving" (Pashak et al., 2014). It is theorized that individuals with a high number of developmental assets are more likely to exhibit success or thriving behavior in the future (Pashak et al., 2014; Chew, Osseck, Raygor, EldridgeHouser, \& Cox, 2009). Conversely, youth who have less developmental assets are more likely to engage in risk behaviors (Pashak et al., 2014). For each category on the DAP, there is a total possible score of 30 and a minimum score of 0 . As determined by the Search Institute, the scores are grouped accordingly: Challenged (0-14), Vulnerable (15-20), Adequate (21-25), and Thriving (26-30). For this study, only the empowerment asset was utilized (items 17, 21, 25, 29, 36) (Bay-Cheng, 2012).

Demographics were analyzed by questions 3-7 on the DAP and questions 1-3 on the Rosenberg Self-Esteem Scale.

\section{Limitations}

This study examined all participants in the CYFAR after school program that were African American females and their self-reported feelings of self-esteem and empowerment. Therefore, there could have been some discrepancy on what the youth actually feel about themselves and how they were feeling the day data were collected. Some students may not have been willing to divulge personal information even though their confidentiality was assured. Another limitation is the sample size, which is relatively small and may not be as generalizable as a larger sample. Additionally, the sample used for the study was not random, but a sample of convenience. The possibility of the program curriculum affecting the answers of the youth is also possible. Another limitation would be the lack of repeat participants in the program each year. Repeat participants in the program for multiple years in a row could give the researcher a better comparison of their feelings over time. However, it is the nature of after-school programs to have changing enrollments.

\section{Data Analysis}

Descriptive statistics were used to examine the distribution responses of all the data entered to help identify any data that was incorrect or outlying. Next, a total score for the factors selfesteem and empowerment using the items on the DAP and the Rosenberg was created. An analysis of variance (ANOVA) was conducted to compare mean scores of empowerment and self-esteem of the three one-year female cohort groups. Lastly, Pearson correlations were conducted in order to examine the relationship between the two variables self-esteem and empowerment for the three one-year female cohort groups. Analyses were performed with SPSS 22.0.

\section{Demographics}

A combined total of 136 students comprised the three one-year cohort groups for this study. Of the total sample $(n=136)$, which included both male and female youth, $47.8 \%(n=65)$ were self-reported as male and $52.2 \%(n=71)$ self-reported as females. The total population (males and females; $n=136$ ) ranged between the ages of ten and nineteen. Of the 71 female youth respondents, 94.4\% $(n=67)$ were African American, $2.8 \%(n=2)$ were White, $2.8 \%(n=2)$ were American Indian or Alaskan Native, and $0 \%$ were Hispanic. Only African American females were 
examined for the purpose of this study. Thus, the total population examined was 67 African American female youth.

Within the African American female youth population $(n=67)$, the following ages were reported: ten years $(1.4 \%)$; eleven years $(26.8 \%)$; twelve years $(26.8 \%)$; thirteen years $(18.3 \%)$; fourteen years $(15.5 \%)$; fifteen years $(7.0 \%)$; and seventeen years $(4.2 \%)$. The mean age was $12.58(\mathrm{SD}=1.57)$.

\section{Self-Esteem}

The levels of self-esteem for the total population were measured for the three cohort groups using the Rosenberg Self-Esteem Scale (Rosenberg, 1965). The frequency of total self-esteem scores among African American female youth of the combined cohort group across three years in an after school program varied. Of the African American female population $(n=55)$, only three respondents indicated scores below 15 (5.5\%); one in the second cohort group and two in the third cohort groups (Table 1). Thirty-two respondents from the combined cohorts group fell in the normal range (58.2\%); 20 were in the high range (36.4\%); and 16 responses were missing. The mean self-esteem score for the combined cohort groups was $23.30(S D=4.7$, indicating the population had overall normal to high levels of self-esteem at the time of collection.

For this female sample, the Cronbach's Alpha score of the scale was .793, which is consistent with historical Cronbach's Alpha scores found when using the Rosenberg Self-Esteem Scale (Rosenberg, 1965).

Table 1

African American Female Cohort Group Self-Esteem Scores

\begin{tabular}{|l|c|c|c|c|}
\hline & Cohort Group 1 & Cohort Group 2 & Cohort Group 3 & Total \\
\hline Low & $0(0.0 \%)$ & $1(4.3 \%)$ & $2(10.5 \%)$ & $3(5.5 \%)$ \\
\hline Normal & $9(69.2 \%)$ & $12(52.2 \%)$ & $11(57.9 \%)$ & $32(58.2 \%)$ \\
\hline High & $4(30.8 \%)$ & $10(43.5 \%)$ & $6(31.6 \%)$ & $20(36.4 \%)$ \\
\hline Total & $13(100.0 \%)$ & $23(100.0 \%)$ & $19(100.0 \%)$ & $55(100.0 \%)$ \\
\hline
\end{tabular}

The first research question for this study asked: Is there a statistically significant difference in the self-esteem levels of three one-year cohort groups of African American female youth participants in an after school program? The researchers hypothesized that there would be a statistically significant difference in the self-esteem levels of three one-year cohort groups of African American female youth participants in an after school program. A one-way ANOVA of self-esteem revealed no statistically significant difference in female cohort groups in the after school program, $\mathrm{F}(2.51)=.156, \mathrm{p}=.856$. Therefore, the hypothesis was not accepted.

\section{Empowerment}

The Development Assets Profile (DAP) (1995) is a research tool used to understand the strengths and supports (developmental assets) that young people experience at any given point 
in their life. For this study, only empowerment items were examined and scored consistent with the Search Institute's guidelines.

All three female cohort groups fell into the "vulnerable" $(n=40 ; 59.7 \%)$ and "challenged" $(n=27 ; 40.3 \%)$ categories, with none falling into the "adequate" or "thriving" categories. The mean empowerment score for the female cohort groups combined was $14.97(\mathrm{SD}=2.855)$. The empowerment scores for each cohort group were also examined (Table 2). In cohort group 1, $9(33.3 \%)$ of respondents fell into "challenged" category and $18(66.6 \%)$ of respondents fell into the "vulnerable" category. In cohort group 2, $11(47.8 \%)$ of respondents fell into the "challenged" category and 12 (52.2\%) fell into the "vulnerable" category. In cohort group 3, 7 $(41.2 \%)$ of respondents fell into the "challenged" category and $10(58.8 \%)$ fell into the "vulnerable" category.

Table 2

African American Female Cohort Group Empowerment Scores

\begin{tabular}{|l|c|c|c|c|}
\hline & Cohort Group 1 & Cohort Group 2 & Cohort Group 3 & Total \\
\hline Challenged & $9(33.3 \%)$ & $11(47.8 \%)$ & $7(41.2 \%)$ & $30(42.3 \%)$ \\
\hline Vulnerable & $18(66.6 \%)$ & $12(52.20 \%)$ & $10(58.8 \%)$ & $41(57.7 \%)$ \\
\hline Total & $27(100 \%)$ & $23(100 \%)$ & $17(100 \%)$ & $71(100 \%)$ \\
\hline
\end{tabular}

For this female sample, the Cronbach's Alpha score for the DAP items was .766. This score is consistent with reports from the Search Institute who reported an alpha score of .77 (Search Institute, 2013).

The second research question of this study asked: Is there a statistically significant difference in the empowerment levels of three one-year cohort groups of African American female youth participants in an after school program? The researchers hypothesized that there would be a statistically significant difference in the empowerment levels of three one-year cohort groups of African American female youth participants in an after school program. A one-way ANOVA of empowerment revealed no statistically significant difference in female cohort groups in the after school program, $\mathrm{F}(2,66)=1.20, \mathrm{p}=.308)$; therefore, the hypothesis was not accepted.

The third research question pertained to self-esteem and empowerment: Is there a statistically significant relationship between the variables of self-esteem and empowerment for three oneyear cohort groups of African American female youth participants in an after school program? The researchers hypothesized there would be a statistically significant relationship between selfesteem and empowerment for three one-year cohort groups of African American female youth participants in an after school program. Pearson correlations were conducted in order to examine the relationship between the variables of self-esteem and empowerment of the three female cohort groups. A statistically significant positive relationship between self-esteem and empowerment $(r=.299, p=.031)$ was present. Therefore, the hypothesis was accepted. 


\section{Discussion}

This study examined three research questions and the implications of each question's results. The first research question examining self-esteem differences in cohort groups did not yield statistically significant results. This resulted in the rejection of the hypothesis. This finding was interesting because of the research literature supporting the idea that after school programs promote positive self-esteem and outcomes (John, Wright, Rowe, \& Duku, 2009; Eccles \& Gootman, 2002; Mahoney, Larson, \& Eccles, 2005; John et al., 2009). However, the initial selfesteem scores of the participants in each cohort group were normal/high, so the lack of increase is not necessarily a negative outcome. If the scores of each individual cohort group were low and remained low, this would be cause for concern.

The three female cohort groups are also primarily not repeat participants in the program. The lack in changes of levels of self-esteem could be largely due to this. From the baseline year (year 1), there were no significant changes, but also no decline. This is a good sign considering the high-risk nature of the population and indicates that despite their low SES, the youth still feel good about themselves. Low socioeconomic status can contribute to the lack of self-esteem and can also be a risk factor for the participation in risk behaviors (Rhodes, Roffman, Reddy, Fredrikson \& Way, 2004). It is difficult to understand why this population has consistently high levels of self-esteem entering the program given their exposure to risk factors. The data supports the conflicting research that is continuously trying to examine why this population is not showing more depressive and anxious feelings and behaviors as a result of their contextual circumstances (Gaylord-Hardin et al., 2006). Where they live is only one factor that could possibly hinder them and does not take into account all the other possible factors like deviant peers, lack of adult support, and access to drugs and alcohol. Possibly, they may have positive self-esteem because of their comfort with peers that have the same background in the program. They also may participate in negative behaviors and still feel good about it because it is the community norm.

Investigation of the second research question on empowerment level differences between cohort groups did not yield significant results, similar to the first research hypothesis. Unlike the relatively high self-esteem scores for each cohort group, the empowerment scores indicated that participants are lacking a sense of empowerment.

In the conceptualization of empowerment, there are two major levels of youth perceptions that can affect their feelings of empowerment. The first is personal, or how safe the youth feels in the community and how much of a role they believe they are playing in the community (Scales \& Leffert, 1999). Research has also found that youth who have a strong sense of feeling valued and perceiving they have useful roles have strong associations with higher self-esteem and selfconcept, greater sense of personal control or sense of optimism about the future, greater achievement of self-actualization, reduced delinquency, greater perception of safety at school, higher levels of thinking, increased social skills, decreased school failure, reduced substance abuse, and greater participation in community activities (Scales \& Leffert, 1999). An imbalance in these two perceptions would lead to lack of empowerment.

The mean age for the three cohort groups combined was $12.58(\mathrm{SD}=1.57)$. This age falls in the early adolescence stage, where the view of the "self" becomes more negative and identity confusion peaks (Tuijl et al., 2014). It is not surprising that empowerment scores for this 
population started significantly lower in relation to the self-esteem scores of the population based on these two ideas alone. An imbalance in the perceptions that contribute to feelings of empowerment, in a stage of adolescence when the "self" is most vulnerable to negativity could possibly explain the over all low scores of each cohort group.

The final research question addressed a correlational relationship between the two variables self-esteem and empowerment. There was a significant positive relationship between the variables self-esteem and empowerment. This result led to the acceptance of the research hypothesis. Since both self-esteem and empowerment are heavily rooted in the idea of "self," it makes sense that there is a relationship between them. Causation between variables cannot be established, but we can establish that they are affecting each other. Further research into this relationship may allow for a better conclusion as to which variable is affecting the other. Since after school programs cater increasing both feelings of self-esteem and empowerment, it does not seem that one would be increased more than the other.

\section{Self-Esteem and After School Programs}

The population examined in this study was a high risk African American female population, whose self-esteem measures were high at the time of initial enrollment in the after school program. There are no program impact associations that can be established from this data, but after school programs have historically provided many resources that promote healthy selfesteem (John, Wright, Rowe, \& Duku, 2009; Eccles \& Gootman, 2002; Mahoney, Larson, \& Eccles, 2005; Loughlin, Barnett, Culen, Stedman, Payne-Purvis, 2013; Barnett, Neely, PaynePurvis, Culen, 2014). Since the self-esteem scores of this population are already normal to high, the after school program can help them maintain their levels of self-esteem with continued support and guidance. This is especially important as the youth get older and start making decisions about their lives during and after high school, and in particular, as they progress into advanced adolescent stages and are faced with decisions about risk behaviors.

In the community where the after school program was implemented, there was also an elementary school after school program ( $\mathrm{K}-5^{\text {th }}$ grade). The program's curriculum could have contributed to the high self-esteem scores of the population that then moved on to the older students' after school program. The elementary program impact has not been measured. In the conceptualization of possible explanations for the high levels of self-esteem in such an at-risk population, this is just one possible contributing factor.

\section{Empowerment and After School Programs}

Based on the examinations made in this study, the baseline empowerment scores for each cohort group are very low. After school programs provide many resources that promote positive self-concepts and guidance. Like self-esteem, empowerment can be increased because of the participation in after school programs. Empowerment is also heavily connected to self-efficacy. When feelings of empowerment are higher, an individual could develop more self-efficacy and actually perform more tasks with a high amount of effort. It is not surprising that this specific female population does not have a high sense of empowerment because of the heavy community factors that affect it. An imbalance between the youth and the community in which they live can be a huge factor in why they are not feeling empowered (Scales \& Leffert, 1999). 
The female cohort group in this study classified as "vulnerable" based on their empowerment scores established by the DAP (1995). Vulnerable youth are those with the fewest developmental assets. This population has also been found to be helped more than youth with average to high levels of assets by the broader opportunities available in healthy communities, or communities where youth problem statistics are low (Scales \& Leffert, 1999). Blythe and Leffert (1995) found that vulnerable youth in healthy communities are less likely to engage in risk behaviors than equally vulnerable youth in unhealthy communities. This is where after school staff must be aware of their population and their possible impact as a staff.

Since after school programs can provide the environment to develop or maintain a positive sense of self and ultimately build empowerment, future research on these topics could focus on pre and post test analysis on empowerment measures and see the initial empowerment scores and any changes after completing an after school program curriculum. Participants should also be better monitored in terms of who are repeat participants in the program and who are not. This would allow for more longitudinal style analyses and comparisons between groups. A larger sample size would also help generalizability. Further research could also explore self-esteem (what an adolescent feels about themself) and self-concept (what an adolescent thinks about themself) to determine links between affective and cognitive domains of the self.

For after school staff, the results for this study are especially important. To be aware of the initial self-concepts of their students could help them identify how to further guide the youth and help them improve their self-concepts, especially in the area of empowerment. The lack of empowerment is largely due to the imbalance of both personal and abstract perceptions of youth. The more abstract perceptions come with ideas like not having a voice, or not feeling heard by adults in the community. After school staff can help this by first making the youth feel like they have a voice. By gaining a voice and learning how to use the after school program resources, youth can begin to feel more empowered and also maintain this feeling. Since adults are huge factors in how empowered youth feel, the staff must understand this and use it to their advantage.

\section{Summary}

The results of this study indicated no significant relationship between the after school program and feelings of self-esteem and empowerment for each cohort group. There was a correlation, however, between the self-esteem and empowerment within participant cohort groups. This relationship was positive, but did not show which variable determined the direction. This is significant because of the opportunity to build more positive self-esteem for youth participating in programs such as this one and that are also closely related demographically. The benefits of after school programs can be utilized and give higher risk youth the opportunity to keep building on the foundation they already have in terms of how they feel about themselves, and build even more self-esteem and empowerment. The results of this study can be used to both improve and reiterate the effects of after school programs. While there was no significance between scores, the high self-esteem scores in each cohort group serves as a positive and hopeful starting point for the improvement of after school programs. This study does support the evidence that after school programs promote and help maintain positive sense of "self" and their feelings of self-esteem and empowerment. 


\section{References}

Agarwala, S., \& Raj, P. (2003). Relation of self-esteem with behavioural problems and school performance of children: A behaviour modification approach. Psychological Thought.

Arnett, J. (2010). Bridging culturan and developmental approaches to psychology: New syntheses in theory, research, and policy. 255-275.

Bandura, A. (1977). Social learning theory. Englewood Cliffs, NJ: Prentice-Hall.

Bandura, A. (1986). Social foundations of thought and action. Englewood Cliffs, NJ: PrenticeHall.

Bandura, A. (1997). Self-efficacy: The exercise of control. New York: W.H. Freeman.

Barnett, R.V., Neely, J.C., \& Culen, G.R. (2014). At-risk youth in after-school programs: How does their use of media for learning about the community issues relate to their perceptions of community connectedness, community involvement, and community support? Journal of Youth Development Special Issue: Media and Youth Development: An Overview of Issues, Theory and Research, 9(1), 159-176.

Bay-Cheng, L.Y. (2012). Recovering empowerment: De-personalizing and re-politicizing adolescent female sexuality. Sex Roles, 66, 713-717.

Bhattacharjee, A., \& Deb, S. (2007). Suicidal tendencies among depressive patients. Journal of the Indian Academy of Applied Psychology, 33(2), 213-218

Blythe, D.A., \& Leffert, N. (1995). Communities as contexts fro adolescent development: An empirical analysis. Journal of Early Adolescent Research, 10, 64-87.

Boden, J.M., Fergusson, D.M. \& Horwood, L.J. (2008). Does adolescent self-esteem predict later life outcomes? A test of the causal role of self-esteem. Development and Psychopathology, 20, 319-339.

Bos, A.E.R., Huijding, J., Muris, P., Vogel, L.R.R., \& Biesheuvel, J. (2010). Global, contingent and implicit self-esteem and psychopathological symptoms in adolescents. Personality and Individual Differences, 48(3), 311,316.

Brausch, A.M., \& Decker, K.M. (2014). Self-esteem and social support as moderators of depression, body image, and disordered eating for suicidal ideation in adolescents. Journal of Abnormal Child Psychology, 42, 779-789.

Bryman, A. Social Research Methods. (2012). $4^{\text {th }}$ ed. New York: Oxford University Press.

Cassidy, E., \& Stevenson, H. (2005). They wear the mask: Hypervulnerability and hypermasculine aggression among African American males in an urban remedial disciplinary school. Journal of Aggression, Maltreatment and Trauma, 11, 53-74. 
Chavis, A.M. (2011). Social learning theory and behavioral therapy: Considering human behaviors within the social and cultural context of individuals and families. Social Work in Public Health, 26, 471-481.

Choquet, M., Kovess, V., \& Poutignat, N. (1993). Suicidal thoughts among adolescents: An intercultural approach. Adolescence, 28, 649-659.

Crockenberg, S., \& Soby, B. (1994). Self-esteem and teenage pregnancy. The social importance of self-esteem, (pp. 125-164).

Eccles, J., \& Gootman, J.A. (Eds.). (2002). Community programs to promote youth development. Washington, DC: National Academies Press.

Garmezy, N. (1993). Children in poverty: Resilience despite risk. Psychiatry, 56 (1), 127-136.

Greene, M.L., \& Way, N. (2005). Self-esteem trajectories among ethnic minority adolescents: A growth curve analysis of the patterns and predictors of change. Journal of Research on Adolescence, 15, 151-178.

Gullotta, T.P., \& Adams, G.R. (2005). Handbook of adolescent problematic behavior: Evidence based approaches to prevention and treatment. Springer Science: NY, New York.

Hall, R. (2009). Cool pose, black manhood, and juvenile delinquency. Journal of Human Behavior in the Social Environment, 19, 531-539.

Harris-Brit, A., Valrie, C.R., Kurtz-Costes, B., \& Rowley, S.J. (2007). Perceived racial discrimination and self-esteem in African American youth: Racial socialization as a protective factor. Journal of Research on Adolescence, 174), 669-682.

Hatcher, J. (2007). The state measurement of self-esteem of African American women. Journal Of Transcultural Nursing, 18, 224-232.

John, L., Wright, R., Rowe, W.S., \& Duku, E. (2009). Effects of an after-school art program on youths in low-income communities: A comparative study of Canadian and American youths. Best Practices in Mental Health, 5(1), 75-88.

Lamb, S., \& Peterson, Z.D. (2012). Adolescent females' sexual empowerment: Two feminists explore the concept. Sex Roles, 66, 703-712.

Lee, C., Dickson, D.A., Conley, C.S., \& Holmbeck, G.N. (2014). A closer look at self-esteem, perceived social support, and coping strategy: A prospective study of depressive symptomatology across the transition to college. Journal of Social and Clinical Psychology, 33(6), 560-585.

Lindsey, T.B. (2013). "One time for my females": African-american femalehood, empowerment, and popular visual culture. Journal of African American Studies, 17, 22-34. 
Loughlin, T.M., (Author), Culen, G.R., Stedman, N.L.M., \& (Author) (2013). Self-esteem and feelings of community connectedness of at-risk adolescents attending community based afterschool programs. Journal of Youth Development, 8(1), 78-92. Mahoney, J.L., Larson, R.W., \& Eccles, J. (2005). Organized activities as contexts of development: Extracurricular activities, after-school and community programs. Psychology Press.

Mahoney, J., Larson, R., \& Eccles, J. (Eds.). Organized activities as contexts of development. Hillsdale, NJ: Erlbaum.

Mandara, J., Gaylord-Harden, N.K., Richards, M.H., \& Ragsdale, B.L. (2009). The effects of changes in racial identity in African American adolescents' mental health. Child Development, $80(6), 1660-1675$.

Matthews, J., Kizzie, K., Rowley, S., \& Cortina, K. (2010). African Americans and males: Understanding the literacy gap, tracing academic trajectories, and evaluating the role of learning-related skills. Journal of Educational Psychology, 102, 757-771.

Miller, D., \& Lavin, F. (2007). 'But now I feel I want to give it a try': formative assessment, selfesteem and a sense of competence. Curriculum Journal, 18(1), 3-25.

doi:10.1080/09585170701292109

National Crime Records Bureau. (2007). Accidental deaths and suicides in India. Retrieved from ncrb.nic.in/accdeaths.htm.

O'Dea, J.A., \& Abraham, S. (2000). Improving the body image, eating attitudes, and behaviors of young make and female adolescents: A new educational approach that focuses on selfesteem. 44-57.

Orth, U., Robins, R.W., Trzesniewski, K.H., Maes, J., \& Schmitt, M. (2009). Low self- esteem is a risk factor for depressive symptoms from young adulthood to old age. Journal of Abnormal Psychology, 118(3), 472-478.

Orth, U., Robins, R.W., \& Roberts, B.W. (2008). Low self-esteem prospectively predicts depression in adolescence and young adulthood. Journal of Personality and Social Psychology, $95,695-708$.

Pashak, T.J., Hagen, J.W., Allen, J.M., Selley, R.S. (2014). Developmental assets: Validating a model of successful adaptation for emerging adults. College Student Journal, 48(2), 243-248.

Paxton, S.J., Eisenberg, M.E., \& Neumark-Sztainer, D. (2006). Prospective predictors of body dissatisfaction in adolescent females and males: A five year longitudinal study. Developmental Psychology, 42(5), 888-899.

Pyszczynski, T., Greenberg, J., Solomon, S., Arndt, J., \& Schimel, J. (2004). Why do people need self-esteem? A theoretical and empirical review. Psychological Bulletin, 130, 435-468.

Rhodes, J.E. (2004). The critical ingredient: Caring youth-staff relationships in after-school settings. New Directions for Youth Development, No. 101, 145-161.

Rosenberg, M. (1965). Society and the adolescent self-image. Princeton, NJ: Princeton University Press. 
Scales, P.C., \& Leffert, N. (1999). Developmental assets: a synthesis of the scientific research on adolescent development. Minneapolis, MN: Search Institute.

Scales, P.C. Benson, P.L., Dershem, L., Fraher, K., Makonnen, R., Nazneen, S., Syvertsen, A.K., \& Titus, S. (2013). Building developmental assets to empower adolescent girls in rural Bangladesh: Evaluation of project "Kishoree Kontha." Journal of Research on Adolescence, 23(1), 171-184.

Sharma, S., \& Ararwala, S. (2013). Contribution of self-esteem and collective self-esteem in predicting depression. Psychological Thought, 6(1), 117-123.

Schmitt, D.P., \& Allik, J. (2005). Simultaneous administration of the Rosenberg Self-Esteem Scale in 53 nations: Exploring the universal and culture-specific features of global self-esteem. Journal of Personality and Social Psychology, 89, 623-642.

Sharaf, A.Y., Thompson, E.A., \& Walsh, E. (2009). Protective effects of self-esteem and family support on suicide risk behaviors among at- risk adolescents. Journal of Child \& Adolescent Psychiatric Nursing, 22(3), 160-168.

Swinton, A., Kurtz-Costes, B., Rowley, S., \& Okeke-Ade-yanju, N. (2011). A longitudinal examination of African American attributions about achievement outcomes. Child Development, $82,1486-1500$.

Travis, R., Leech, T.G.J. (2013). Empowerment-based positive youth development: A new understanding of healthy development for African American youth. Journal of Research on Adolescence, 24(1), 93-116.

Tuijl, L.A. Jong, P.J., Sportel, E.B., Hullu, E., \& Nauta, M.H. (2014). Implicit and explicit self-esteem and their reciprocal relationship with symptoms of depression and social anxiety: A longitudinal study in adolescents. Journal of Behavioral Therapy \& Experimental Psychiatry, 45, 113-121.

Urban, R., Szigeti, R., Kokonyei, G., \& Demetrovics, Z. (2014). Global self-esteem and method effects: Competing factor structures, longitudinal invariance, and response styles in adolescents. Behavior Research, 46, 488-498.

Vanhalst, J., Luyckx, K., Sholte, R.H., Engels, R., \& Gossens, L. (2013). Low self-esteem as a risk factor for loneliness in adolescence: Perceived-but not actual-social acceptance as an underlying mechanism. Journal of Abnormal Child Psychology, 41, 1067-1081.

Werner, E.E., \& Smith, R.S. (1992). Overcoming the odds: High risk children from birth to adulthood. Ithaca, NY: University Press.

(C) Copyright of Journal of Youth Development Bridging Research and Practice. Content may not be copied or emailed to multiple sites or posted to a listserv without copyright holder's express written permission. Contact Editor at: patricia.dawson@oregonstate.edu for details. However, users may print, download or email articles for individual use.

ISSN 2325-4009 (Print) 